\title{
Cholesterol anchors enable efficient binding and intracellular uptake of DNA nanostructures
}

\author{
William L Whitehouse ${ }^{1}$, James E Noble ${ }^{2}$, Maxim G Ryadnov ${ }^{2}$, Stefan Howorka, ${ }^{2, *}$ \\ ${ }^{1}$ Department of Chemistry, Institute of Structural and Molecular Biology, University College London, London, WC1H 0AJ, \\ United Kingdom. \\ ${ }^{2}$ National Physical Laboratory, Hampton Road, Teddington, TW11 0LW, United Kingdom
}

DNA, Nanotechnology, Cells, Membrane, Endosome, Flow Cytometry, Microscopy.

\begin{abstract}
DNA nanostructures constitute a rapidly advancing tool-set for exploring cell-membrane functions and intracellular sensing or advancing delivery of cargo or drugs into cells. Chemical conjugation with lipid anchors can mediate binding of DNA nanostructures to synthetic lipid bilayers, yet how such structures interact with membranes and internalize cells has not been shown. Here, an archetypal 6-duplex nanobundle is used to investigate how lipid conjugation influences DNA cell binding and internalization kinetics. Cellular interactions of DNA-nanobundles modified with one and three cholesterol anchors were assessed using flow cytometry and confocal microscopy. Nuclease digestion was used to distinguish surface-bound DNA, which is nuclease accessible, from internalized DNA. Three cholesterol anchors were found to enhance cellular association by up to 10-fold when compared with unmodified DNA. The bundles were endocytosed efficiently within $24 \mathrm{~h}$. The results can help design controlled DNA binding and trafficking into cells.
\end{abstract}

Nucleic acids are modified via numerous covalent chemistries to control or enhance their interactions with cell-like ${ }^{1-3}$ and cell membranes. ${ }^{4-6}$ Modifications can improve cell uptake by enhancing duplex stabilization and nuclease resistance. ${ }^{7,8}$ A more direct route to strengthening cell interaction relies on modifying nucleic acids with lipid anchors. ${ }^{5,6,9}$ Alternative routes for membrane binding are to charge-neutralize the DNA backbone, ${ }^{10}$ or to complex DNA non-covalently with membrane-binding and fusing agents such as peptides. ${ }^{11}$ dendrimers, ${ }^{12}$ and polymers. ${ }^{13}$ Among these approaches, modification of nucleic acids with lipid anchors is the best compromise between chemical definition and ease of fabrication.,6,9 Lipid-modified DNA can also anchor cargo to membranes and fuse vesicles to cells ${ }^{14}$ and planar $^{15}$ and curved membranes ${ }^{2,16,17}$ similar to membrane fusion proteins. $^{18-23}$

DNA-nanostructures are an advancing tool-set for research in biology and biomedicine. The nanoarchitectures can probe biological processes, ${ }^{24,25}$ deliver therapeutic cargo $^{26-30}$ or modulate the immune system. ${ }^{31,32}$ The main advantage of DNA nanostructures is the remarkable molecular control over their shape, size, and nanomechanical movement. ${ }^{33-43}$ As a further benefit, the compact nature of nanostructures leads to enhanced stability towards nuclease degradation when compared to linear $\mathrm{DNA}^{44}$ outside and inside cells. ${ }^{45,46}$ A central topic for cell biological applications remains how to control cellular binding and internalization of DNA nanostructures. Uptake and trafficking is known to be influenced by nanostructure size, shape and compactness, as well as cell type. ${ }^{47-49}$ Yet, the role of lipid anchor modification on cell interaction has not been explored. Lipid anchors may, as potential advantage, increase cellular localization. Furthermore, lipidation may be generic route to target cell membranes independent of DNA nanoshape.

Here, we study how cholesterol modifications on DNA nanostructures influence their interaction with biological cells. Lipid-modified nanostructures have previously been studied with model lipid bilayers but not with biological cells. ${ }^{50-67}$ Bio- logical membranes are more complex given their multicomponent lipid composition as well as the presence of many peripheral or integral membrane proteins. Inferring the interaction of lipidated DNA nanostructures with biological membranes from synthetic membranes has to account for these stark bilayer differences.

For our study, a recently devised DNA-nanobundle composed of six interconnected DNA duplexes was selected as model system (Figure 1).$^{53,55}$ The nanostructure is $9 \mathrm{~nm}$ high and $6 \mathrm{~nm}$ wide, and is modified with up to three cholesterol anchors.

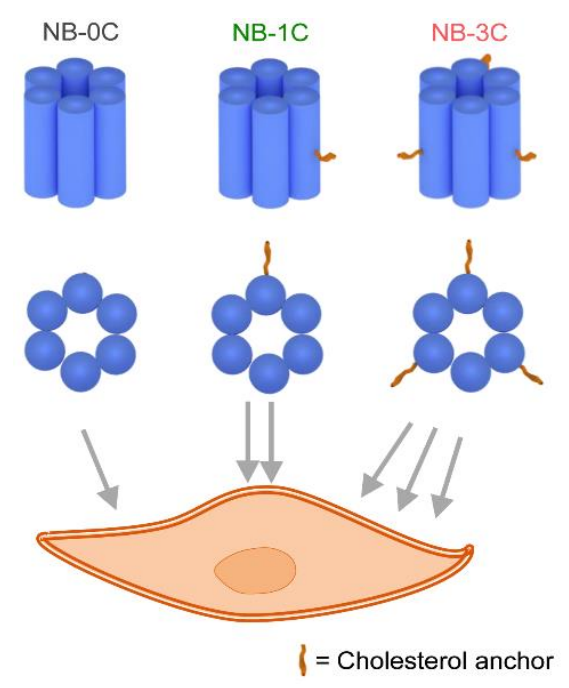

Figure 1. Schematic representation of the nanobundle, their cholesterol modification, and interaction with cells. An archetypal 6-duplex nanobundle is composed of six-interconnected DNA duplexes obtained by self-assembly of six oligonucleotides. Each duplex is twenty-one base pairs long. ${ }^{53,55}$ Hydrophobic cholesterol molecules are attached via a 15-atom triethylene glycol spacer to create DNA nanobundles NB-0C, NB-1C and NB-3C with none, one, or three anchors, respectively. 
Fluorescence activated cell sorting (FACS) and fluorescence microscopy, along with a nuclease digestion assay are used to investigate the effect of modification on cellular binding and uptake kinetics as well as the final intracellular localization.

\section{Results and Discussion}

The Components of our Study. In order to probe the effect of lipid modification on cellular interaction, we used a six-duplex nanostructure with up to three cholesterol anchors attached via tetra-ethylene glycol (TEG) linkers via the DNA 5' terminus at the bundle exterior (Figure 1) ${ }^{53,55}$ Reflecting the number of cholesterols, the structures were termed NB-0C, NB-1C and NB-3C. NB-3C nanobundle has previously been showed to span lipid bilayers as opposed to NB-1C that just tethers to membranes ${ }^{53,54}$. However, due to the chemical and structural complexity of biological cell membranes, one cannot deduce that NB-3C also punctures cells.

To measure nanobundle-cell interactions, Alexaflour-647 was incorporated into the nanostructure at the DNA bundle exterior via the 5' terminus of a non-cholesterol modified DNA strands, as described in ref $^{54}$. Alexafluor has a high fluorescence stability and can, like other fluorophores, partition into the membrane. ${ }^{68}$ However, when conjugated to a negatively charged DNA and compared to the highly hydrophobic cholesterol anchor, the contribution of the fluorophore to membrane binding is deemed to be very small. Alexfluor-modified DNA strands without cholesterol modification were also used as a control.

Nanobundle assembly was validated with agarose and polyacrylamide gel electrophoresis (Figure S1). HeLa cells were selected given their wide use in studies with DNA nanostructures. Finally, two cell media were used to test the interaction of nanostructures with cells. Opti-MEM (minimal essential cell medium) without serum, and DMEM supplemented with $10 \%$ fetal bovine serum (FBS). Serum proteins may interact with nanostructures and thereby influence cell binding. ${ }^{49,69}$ Specifically, it is known that proteins can rapidly cover the surface of inorganic nanoparticle. ${ }^{70,71}$

Influence of Lipid Anchor Number and DNA Nanobundle Concentration on Cellular Interaction. Fluorescence activated cell sorting was used to quantify how lipid anchor number and nanostructure concentration influences cellular association. Nanobundle concentrations of 100 to $0.1 \mathrm{nM}$ were incubated over $3 \mathrm{~h}$ in protein-depleted opti-MEM medium. The strongest increase in cell binding was achieved with the highest nanobundle concentration (Figure 2, Figure S2A).

At this condition, cellular association rose by approx. 4-fold for the nanobundle with one cholesterol anchor compared to the non-modified nanobundle NB-0C. With an additional hour of incubation, two extra cholesterol anchors further increased association by 6 to 10 -fold for NB-3C (Figure 2, Figure S2B). The effect was smaller at $10 \mathrm{nM}$, and negligible at 1 and $0.1 \mathrm{nM}$. The data suggest that cholesterol can mitigate the otherwise electrostatic repulsive interaction between the net-negatively charged DNA structures and similarly charged cancer cell membranes. ${ }^{72,73}$ The compact nature of the DNA nanobundle also had a positive effect on interaction when compared to a flexible control DNA strand. In particular, non-modified nanobundles showed a 290-fold increase in cellular association compared to a 50 nt-long ssDNA that did not carry a cholesterol anchor (Figure S2). The binding was stronger by 1100 and 1700-fold when comparing lipid-anchored NB-1C and NB-3C with ssDNA (Figure S2).

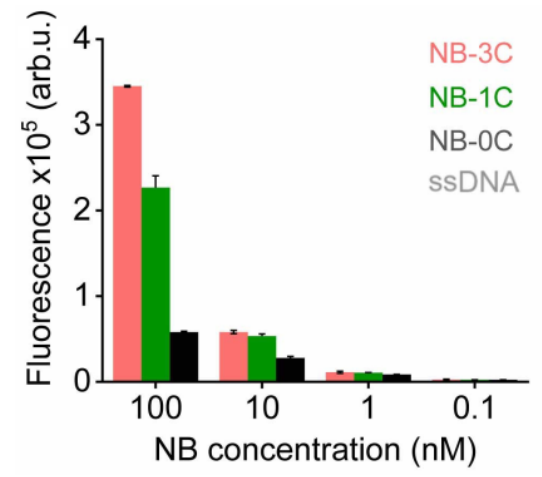

Figure 2. Lipid anchor number and DNA nanobundle concentration effect cellular interaction. In FACS analysis of cell binding, nanobundle variants NB-0C, NB-1C and NB-3C carrying an AlexaFlour-647 fluorophore were incubated in opti-MEM with HeLa cells for $3 \mathrm{~h}$. Cellular interaction was measured as median fluorescence per cell. Fluorophore-tagged ssDNA of $50 \mathrm{nt}$ length was used as a negative control. The binding of ssDNA, after background subtraction, is not visible on the plot.

When the protein-free opti-MEM cell medium was replaced with DMEM+FBS for DNA nanobundle incubation, an approximately 100 - to 200-fold higher increase in cell binding of NB$1 \mathrm{C}$ and $\mathrm{NB}-3 \mathrm{C}$, respectively, relative to NB-0C was observed (Figure S3). The enhancement is by a factor of around 10-20 when compared to protein-depleted opti-MEM. The exact reason for this is not clear, but may be linked to serum proteins mediating and enhancing binding of DNA to cells. The enhancement by FBS was found for cholesterol modified NB-1C and NB-3C but not NB-0C suggesting an additional influence of cholesterol in the binding to the serum protein.

Kinetic Analysis of Nanobundle-Cell Interactions. FACS determined how fast DNA bundles are binding to cells. Kinetics were obtained for 10, 30, 90 and 180 min incubations, using DMEM supplemented with FBS as incubating medium. Fast binding occurred within the first $30 \mathrm{~min}$ followed by a slower phase for all three bundles with no, one and three cholesterol anchors (Figure 3).

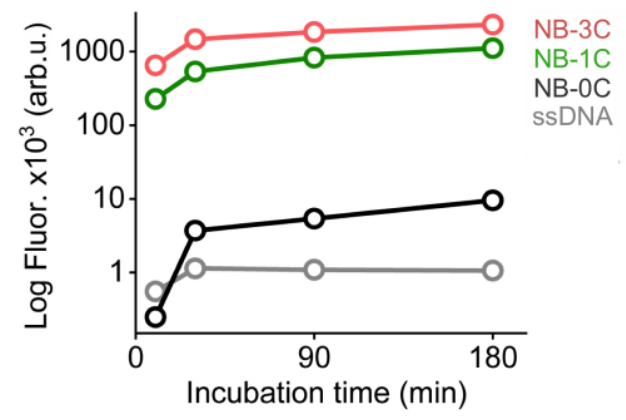

Figure 3. Binding kinetics of cholesterol-modified nanobundles to HeLa cells analyzed with FACS. Plots comparing cellassociation kinetics for AlexaFluor-647-labeled nanobundles; NB-0C, NB-1C and NB-3C that were incubated with cells at a final concentration of $100 \mathrm{nM}$ for the indicated time points. Cells were incubated in DMEM $+10 \%$ FBS medium. Each time-point was measured in triplicate for each nanobundle variant. 
The use of protein-free opti-MEM led to similar binding kinetics yet the difference between the cholesterol-modified and cholesterol-free DNA nanobundles was smaller (data not shown). The following analysis was conducted with opti-MEM.

Membrane Binding vs. Cell Internalization of DNA Nanobundles. The FACS analysis did not reveal whether DNA nanobundles are solely bound to the cell surface or also internalized into cells. Fluorescence microscopy was used to distinguish between membrane-bound vs. internalized bundles as a function of time. In the first 10 min of incubation, NB-3C was localized mostly around cell membranes with more apparent fluorescence observed in membranes at longer incubations (Figure 4). However, prolonged incubation at $30 \mathrm{~min}$ led to appearance of fluorescence signal inside the cells. The signal most probably stems from intact as opposed to fragmented-DNA nanobundles as the compact nanostructures are stable towards nuclease at physiological concentrations. ${ }^{53}$ Uptake into cells was confirmed by Zstack analysis for NB-3C and also NB-1C (Figure S4). Uptake for NB-3C was also shown with XZ/YZ orthogonal cross-sections and 3D-models composed from Z-stacks across single cells (Figure S4).
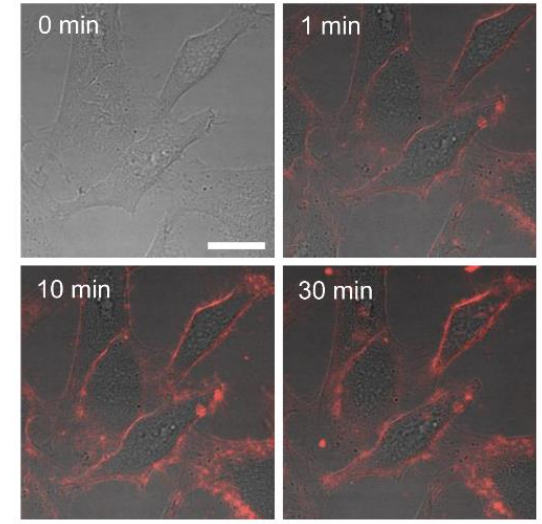

Figure 4. Cholesterol-modified nanobundles bind efficiently to the surface of HeLa cells. Combined fluorescence and dark-field microscopic analysis showing DNA nanobundle binding within 30 min. HeLa cells were incubated with $100 \mathrm{nM} \mathrm{NB}-3 \mathrm{C}$ dissolved in opti-MEM and imaged with fluorescence and bright-field microscopy. Scale bar, $10 \mu \mathrm{m}$.

To obtain quantitative data on the extent of cell surface binding vs. internalization, we used nuclease digestion followed by quantitative FACS analysis. In the assay, nuclease DNAse (I) is added at very high concentrations to digest membrane-associated nanobundle while leaving cell-internalized bundles unaffected. Subsequent fluorescence analysis of nuclease-treated vs. non-treated cells can then reveal the relative amount of internalized vs total bundles. Nuclease digestion disrupts the nanobundle structure which carry the cholesterol and fluorophore attached to different DNA strands.$^{53}$ Consequently, digestion generates DNA fragments carrying no modification, either a lipid or a fluorophore modification, both not both modifications. Fluorophore-modified single-stranded DNA has very low binding to cells as shown below.

Nanobundle digestion was visually validated with fluorescence microscopy. Using a high DNAse (I) concentration of $10 \mathrm{U} / \mathrm{mL}$, most of NB-1C was removed from the cell surface within 10 min (Figure 5). Efficient digestion was also found for NB-3C that localized with the cell membrane (Figure 5, Figures S5 and
S6: confocal images from repeat digestion experiments). The fraction of NB-3C inside cells was, however, higher than for NB-1C (Figure 5, Figures S5 and S6). The difference may be explained by the fact that NB-3C but not NB-1C can span the lipid bilayer ${ }^{53}$ and therefore may have a higher chance of being trafficked into cells. We note that fractions of nanobundles remained membrane associated after $1 \mathrm{~h}$ of digestion (Figures S5 and S6). Furthermore, a few small dead cells have a very high content of DNA nanobundles (Figure 5, Figures S5 and S6). But these are largely discarded by high gating in follow-up FACS analysis.

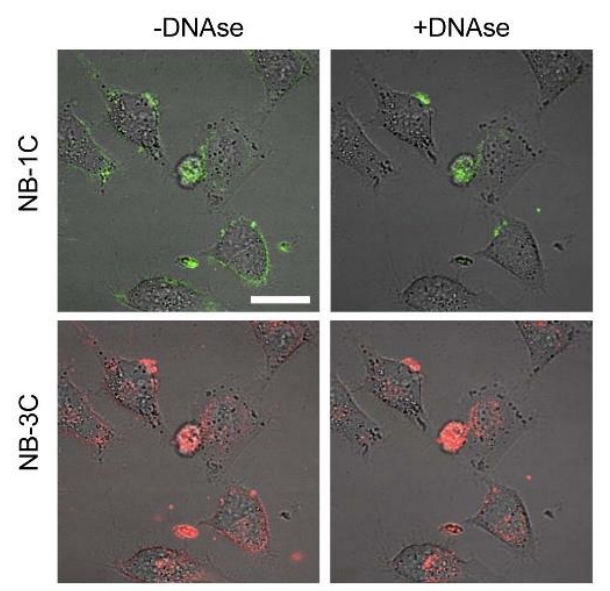

Figure 5. Microscopic Analysis of Nanobundle Binding and Internalization Using Nuclease Digestion. Combined fluorescence and dark-field microscopic analysis on the enzymatic digestion of surface-associated nanobundles. Internalized nanobundles are not digested. Cells were incubated with NB-1C and NB-3C at $100 \mathrm{nM}$ for $2 \mathrm{~h}$ in opti-MEM. NB-3C was tagged with AlexaFluor-647 (red channel) and NB-1C with 6FAM (green channel). Enzyme digestion for $10 \mathrm{~min}$. A dead cell with a high content of DNA nanobundles is apparent in the middle of the image. Scale bar, $10 \mu \mathrm{m}$.

Quantitative information about the fraction of membrane-association vs. internalization was obtained via FACS analysis. Cells were incubated with all three nanobundles for $4 \mathrm{~h}$, followed by nuclease digestion. FACS data revealed that the fraction of internalized NB-3C and NB-1C amounted to $66 \%$ and $62 \%$ of total nanobundles (Figure 6). When comparing to DMEM+FBS, the fraction of internalized nanobundles was considerably smaller, with approximately $10 \%$ of DNA nanobundles NB-1C and NB-3C being internalized (Figures S7).

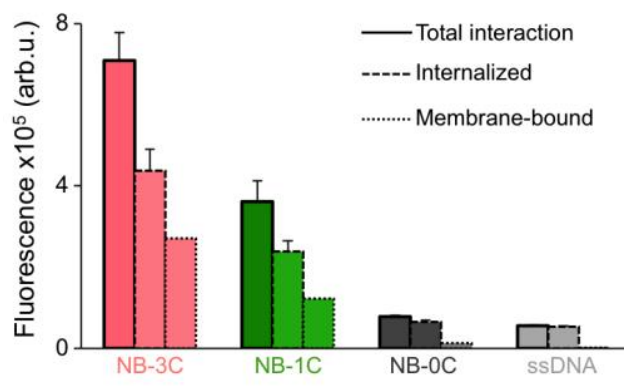

Figure 6. Quantitative Analysis of Nanobundle Binding and Internalization. FACS-derived ratios of nanobundle-cell binding vs. cellular uptake is shown. Cells were incubated with nanobundles at a concentration of $100 \mathrm{nM}$ in opti-MEM without FBS supplementation. After $4 \mathrm{~h}$ incubation, cells were washed with PBS, and subjected to nuclease digestion with DNase (I), $10 \mathrm{U} / \mathrm{mL}$. Total nanobundle-cell interaction was obtained from a non-enzyme treated 
group. Membrane associated fractions were obtained by subtracting enzyme-treated (internalized) from non-treated (total) values. Averages and standard deviations represent results from triplicate readings.

A fraction of $90 \%$ membrane-associated bundles is high and indicates that serum proteins increase the nanobundles' extent of cell binding without corresponding enhanced trafficking into cells. FBS contains more than 20 proteins including albumin as a major component. We hypothesize that nanobundles are likely to complex with proteins via electrostatic interactions. These complexes may enhance binding to cells via cellular proteinrecognition. The larger size of complexes may influence the uptake. ${ }^{49}$ As an additional factor, the expected repulsion between net negatively charged DNA nanostructures and similarly charged cancer cell membranes ${ }^{72}$ could be weakened by charge masking of nanobundles via complexation with serum proteins. Further analyses revealed that binding kinetics were faster than the internalization kinetics, as could be expected for the two sequential processes (Figure S7).

The uptake of the cholesterol-modified DNA nanobundles compares favorably with related studies on other DNA nanostructures. Uptake is dependent on cell-type as well as nanostructure shape, whereby particle size and compactness correlate positively with uptake efficiency. ${ }^{47}$ One reference compound is a DNA-cage of $7 \times 7 \times 7 \mathrm{~nm}$ size which is similar in size to the DNA nanobundle of $5 \times 5 \times 9 \mathrm{~nm}$. This cage required lipofectamin transfection reagent to achieve notable cellular uptake. ${ }^{45}$

Intracellular Localization of DNA Nanobundles. The location of DNA nanobundles after cell uptake was investigated. In general, the intracellular destination of DNA nanostructures can range from the lysosome to the cytosol ${ }^{44,48}$ depending on the trafficking pathway. ${ }^{74,75}$ We clarified the intracellular location of NB-3C DNA nanobundles using fluorescence microscopy. Lysotracker Red, a fluorescent dye for acidic organelles, was used as marker. DNA nanobundles first localized to the cellular membrane and were then internalized within $2 \mathrm{~h}$ (Figure 7, Figure S8).

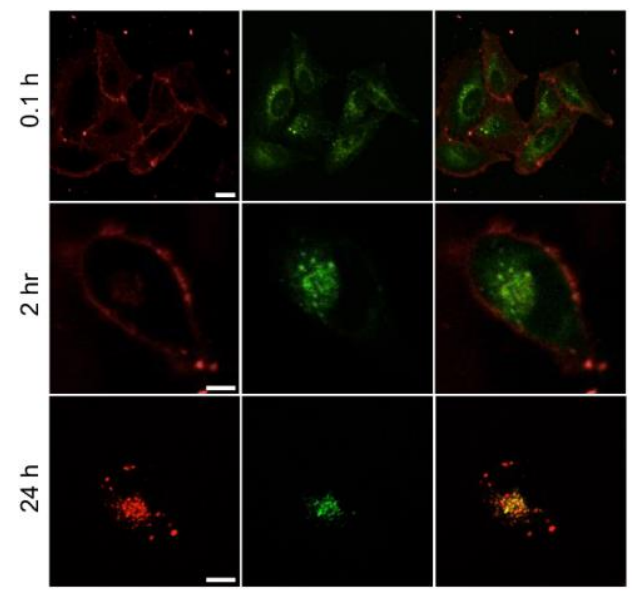

Figure 7. Intracellular localization of DNA nanobundles. Fluorescence microscopy images of cells exposed to Lysotracker (green) and AF647 labelled NB-3C nanobundle (red). Co-localization between NB-3C and endolysosomal compartments was found starting at $2 \mathrm{~h}$ and was completed within $24 \mathrm{~h}$. Cells were incubated in opti-MEM except the $24 \mathrm{~h}$ sample which was incubated in DMEM+FBS after $2 \mathrm{~h}$ to maintain cell viability.
The nanobundle signal co-localized with endolysosomal dye. Incubation for up to $24 \mathrm{~h}$ led to complete uptake and co-localization with the dye suggesting that nanobundles remain within the endolysosomal pathway. The inability to escape from endosomes has been found for numerous other tube-like DNA nanostructures ${ }^{74,75}$ with exception of larger structures with sizes generally greater than $800 \mathrm{~nm} .{ }^{74}$ We note that the endosomal entry of the cholesterol-modified DNA nanobundles is also consistent with the similar uptake of 5'-cholesterol modified oligonucleotides that bind to low-density-lipoprotein that is taken up by receptor-mediated endocytosis. ${ }^{76}$ Incubation of Hela cells with NB-3C followed by observation for $24 \mathrm{~h}$ also confirmed that the cholesterol-modified nanobundles are non-toxic, as determined using a metabolic assay (Figure S9). These findings are different to the limited cytotoxicity of DNA bundles carrying another hydrophobic anchor composed of ethyl-phosphorothioates on the DNA backbone. ${ }^{77}$

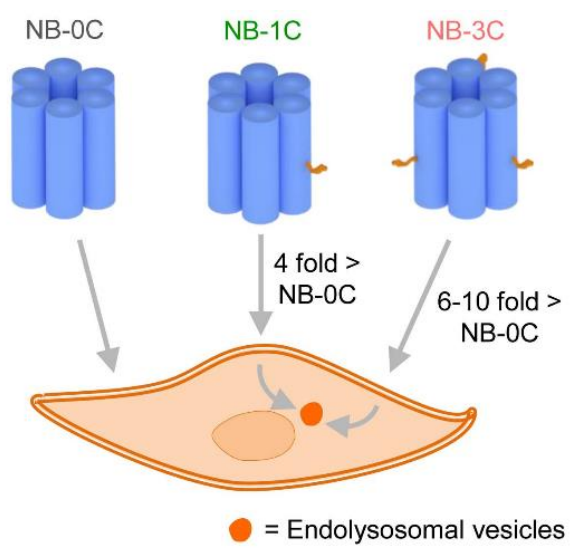

Figure 8. Lipid anchor effect on cellular interaction. A single cholesterol anchor is sufficient to enhance cellular interaction by approximately 4-fold compared to a non-modified structural analogue. Two additional lipid-anchors further enhance cellular interaction from 6 to 10 -fold over NB-0C, marking cholesterol moieties as a viable route to augment nanoparticle-cell association.

\section{Conclusions}

DNA nanostructures are a powerful tool-set for cell biology and biomedicine. To enhance the interaction with bilayer membranes, DNA nanostructures have been equipped with lipid anchors and used for a variety of applications such as to shape $\mathrm{e}^{50,54,57,78}$ or puncture bilayers ${ }^{55,60,64,79-81}$ for bio-sensing, ${ }^{82-85}$ to attain controlled drug release, ${ }^{55}$ to probe membrane interaction forces, ${ }^{86}$ or to alter membrane composition. ${ }^{87}$ Yet, lipidmodified DNA nanostructures have not been examined with cells to explore uptake and internalization. Biological membranes are more complex given their multicomponent lipid composition as well as the presence of many peripheral or integral membrane proteins.

This report provides a novel insight by using an archetypal DNA nanostructure with stoichiometrically and position-controlled cholesterol modifications to study uptake and internalization. The study offers an detailed account how cholesterol tags influence the extent of binding, internalization, and binding kinetics of DNA nanobundles. ${ }^{74}$ Nanobundles with three 
cholesterols increased cell association by up to 10 -fold compared to unmodified bundles (Figure 8). The enhancement was strikingly more than 1000-fold in comparison to flexible ssDNA. Exploring the kinetics revealed an initial rapid binding followed by efficient endocytosis within $24 \mathrm{~h}$. As serendipitous finding, an enhancing effect of serum protein on nanobundle cell binding but not uptake was observed.

NB-3C was preferentially internalized by cells. This nanobunlde can also span synthetic lipid bilayers as opposed to NB-1C that just tethers to membranes. ${ }^{53,54}$ However, due to the chemical and structural complexity of biological cell membranes, one cannot deduce that NB-3C did punctured also these bilayers.

Future research may explore uptake and trafficking pathways, as well as endosomal fate of the DNA nanobundles in relation to their behavior in different media conditions. The intracellular delivery of DNA and proteins is an increasingly attractive topic, ${ }^{88,89}$ and endosomal release can be achieved using a variety of chemical agents, though some levels of toxicity could also be observed. ${ }^{88,90}$ DNA nanostructures may avoid such disadvantages ${ }^{30}$ similar to peptide-based nanostructure that capture and condense nucleic acids. ${ }^{91,92}$ The DNA nanobundle used in our study may represent another route for endosomal release. As the bundle can puncture the membrane with a hollow lumen, ${ }^{55}$ the channel may support the endosomal escape of small molecule cargo such as drugs. In more general terms, the route of lipid-mediated enhancement of cell binding may also be expanded to other DNA nanostructures. In conclusions, this study can help design DNA nanostructures for controlled binding to and trafficking into cells for biological and biomedical applications.

\section{Materials and Methods}

DNA Nanobundle Preparation: The six-duplex nanobundles were prepared following established protocols ${ }^{55}$ and were used within a few $\mathrm{h}$ from folding. Agarose and SDS-PAGE were used to validate nanobundle folding (Figures S1). Sequences of component DNA strands along with 2D DNA maps of the DNA pores have been published. ${ }^{55}$

Cell Culture: HeLa cells were grown in DMEM medium (Invitrogen) supplemented with $10 \%$ heat inactivated FBS (Gibco), 10 $\mu \mathrm{g} / \mathrm{mL}$ gentamicin and $0.25 \mu \mathrm{g} / \mathrm{mL}$ amphotericin B (Invitrogen) at $37^{\circ} \mathrm{C}$ in humidified air containing $5 \% \mathrm{CO}_{2}$.

FACS Analysis on Cell Interaction of DNA Nanobundles: HeLa cells were pre-cultured and used within $24 \mathrm{~h}$ after seeding onto 48 well plates at a density of 25,000 cells per well. Nanobundle stock solutions with a final concentration of $0.1,1,10$ and $100 \mathrm{nM}$ were prepared with Gibco opti-MEM. Prior to sample loading, the cell growth medium (DMEM, 10\% FBS) was aspirated from each well followed by washing thrice with pre-warmed PBS buffer. All samples were pre-warmed to $37{ }^{\circ} \mathrm{C}$ prior to incubation with cells. Samples were then pipetted into wells in triplicate. After $3 \mathrm{~h}$ incubation with nanobundles, samples were aspirated followed by washing twice with PBS. Cells were then trypsinized with TrypLE (Gibco), followed by trypsin inactivation and re-suspension with DMEM and transferal to a 96-well plate. At least 3,000 cells were analyzed for each sample using a FACS Flex-S flow cytometer. Consistent gating based on cell size and granularity (forward and side scatter) was used to select viable single cells for analysis. Median fluorescence intensity (MFI) was calculated for each sample by averaging after background subtraction.

Enzyme-digestion and FACS analysis: Cells were prepared in the same manner as for the concentration assay with the exception that
DMEM 10\% FBS was used as incubating medium. Cells were incubated with nanobundles $100 \mathrm{nM}$ concentration for the desired time duration, followed by $3 \mathrm{x}$ washing with pre-warmed PBS and then exposure to DNase (I) at a final concentration of $10 \mathrm{U} / \mathrm{mL}$ for $1 \mathrm{~h}$. In parallel, control non-enzyme treated cells were incubated with DMEM. Enzyme-treated and non-treated groups were aspirated and washed thrice with PBS, 1X followed by trypsinisation and preparation for FACS analysis following the same procedure as used in the concentration assay.

Fluorescence Microscopy for Nanobundle Binding. HeLa cells were used $24 \mathrm{~h}$ after seeding into 8-well Ibidi glass chambers at a density of 25,000 cells per well. Nanobundle solutions were prepared in the same manner as for FACS experiments and used at a final concentration of $100 \mathrm{nM}$ in opti-MEM reduced serum medium (without FBS supplementation). NB-3C was tagged with AlexaFluor-647 via incorporation of a modified component strand with the fluorophore placed at the 5' end of one oligonucleotide as described. ${ }^{93} \mathrm{HeLa}$ cells were washed $3 \mathrm{x}$ with pre-warmed PBS, $1 \mathrm{X}$ followed by incubation with nanobundles and imaged after the described durations. Images were collected using an Olympus inverted confocal microscope using an oil immersion 60x objective lens. Laser line 633 was used for Alexafluor647 excitation, with appropriate band-pass filters.

Microscopic Analysis of Enzyme-Treated Cells: Nanobundles were incubated with HeLa cells following the same method as used for the localization experiments, with the exception that NB-1C was tagged with 6FAM and co-incubated alongside NB-3C at final concentrations of $100 \mathrm{nM}$. For enzymatic digestion of membrane surface-associated nanobundles, DNase(I) enzyme was prepared in the same method as with FACS experiments and incubated with cells after washing twice with PBS, 1X. Laser lines 633 and 488 were used for AF647 and 6FAM excitation respectively.

Fluorescence Microscopy for Nanobundle Localisation. Nanobundle preparation and incubation was carried out with the same method as with previous microscopy experiments. For endosomal staining, nanobundle (NB-3C) samples were aspirated off after the desired incubation duration, washed twice with PBS, $1 \mathrm{X}$ and incubated for $1 \mathrm{~h}$ with LysoTracker Red DND-99 (Thermo Fisher). LysoTracker was prepared to a final concentration of $100 \mathrm{nM}$ in phenol containing DMEM. LysoTracker containing solution was aspirated off prior to imaging, followed by washing thrice with PBS, $1 \mathrm{X}$ and re-incubation in opti-MEM for imaging. Images were collected using an Olympus inverted confocal microscope using an oil immersion 60x objective lens. Laser lines 633 and 559 were used for AF647 and LysoTracker excitation, respectively, using appropriate band-pass filters.

Cell viability assay. NB-3C nanobundle samples were prepared at a final concentration of $500,250,125$ and $60 \mathrm{nM}$ by diluting in DMEM $+10 \%$ FBS. Required volumes of PBS were added to each DMEM-nanobundle sample to ensure consistent PBS concentration across the assay. As nanobundles were assembled in PBS, the same buffer was selected for use as negative control. Cells were grown to confluence and then seeded into a 96-well plate at a density of 10,000 cells per well. NB-3C samples were incubated with cells for $1 \mathrm{~h}$, followed by washing thrice with PBS, and re-incubation with DMEM+10\% FBS. After $24 \mathrm{~h}$, fluorescence was measured using Alamar Blue metabolic activity assay following manufacturer protocol. Data was collected using a Fluorostar Omega plate reader (BMG Labtech).

\section{ASSOCIATED CONTENT}

\section{Supporting Information}


The Supporting Information is available free of charge on the ACS Publications website at DOI: 10.1021/acs.bioconj- chem.XXXXX.

Gel electrophoretic analysis of DNA nanobundle assembly; Dependence of cell binding depends on lipid anchor number and concentration of DNA nanobundles; FACS data on the interaction of DNA nanobundles to cells; Nanobundle cell internalization visualized by fluorescence microscopy and 3D-model reconstruction; Nanobundle interaction with HeLa cells visualized with fluorescence microscopy; Fluorescence microscopy reveals enhanced uptake of NB3C over NB1C as assayed by DNase (I) digestion of surface-bound DNA nanobundles; FACS-based kinetics analysis on the cellular binding and internalization of DNA nanobundles; Uptake kinetics comparison visualized with fluorescence microscopy; Cell viability of Hela cells incubated with NB-3C.

\section{Author Contributions}

The manuscript was written through contributions of all authors. All authors have given approval to the final version of the manuscript.

\section{ACKNOWLEDGMENT}

We thank Paula Vila Gomez for assistance in cell culture preparations. We acknowledge funding from the UK's Department for Business, Energy and Industrial Strategy and the UK's EPSRC for an industrial case award to W.W. S.H. is supported by the EPSRC (EP/N009282/1), the BBSRC (BB/M025373/1 and BB/N017331/1), and the Leverhulme Trust (RPG-2017-015).

\section{ABBREVIATIONS}

NB-0C, NB-1C, NB-3C, nanobundle with zero, one and three cholesterol anchors, respectively. FACS, Fluorescence activated cell sorting. FBS, Fetal Bovine Serum. Opti-MEM, optimal-Minimal Essential Medium. DMEM, Dulbecco's Modified Eagles Medium.

\section{REFERENCES}

(1) Lopez, A., and Liu, J. (2018) DNA oligonucleotidefunctionalized liposomes: Bioconjugate chemistry, biointerfaces, and applications. Langmuir 34, 15000-15013.

(2) Yoshina-Ishii, C., and Boxer, S. G. (2003) Arrays of mobile tethered vesicles on supported lipid bilayers. J. Am. Chem. Soc. 125 3696-3697.

(3) Ugarte-Uribe, B., Grijalvo, S., Pertinez, S. N., Busto, J. V., Martin, C., Alagia, A., Goni, F. M., Eritja, R., and Alkorta, I. (2017) Lipid-modified oligonucleotide conjugates: Insights into gene silencing, interaction with model membranes and cellular uptake mechanisms. Bioorg. Med. Chem. 25, 175-186.

(4) Moulton, H. M., Nelson, M. H., Hatlevig, S. A., Reddy, M. T., and Iversen, P. L. (2004) Cellular uptake of antisense morpholino oligomers conjugated to arginine-rich peptides. Bioconjug. Chem. $15,290-299$

(5) Raouane, M., Desmaele, D., Urbinati, G., MassaadMassade, L., and Couvreur, P. (2012) Lipid conjugated oligonucleotides: A useful strategy for delivery. Bioconjug. Chem. 23, 1091-1104.

(6) Gissot, A., Camplo, M., Grinstaff, M. W., and Barthelemy, P. (2008) Nucleoside, nucleotide and oligonucleotide based amphiphiles: A successful marriage of nucleic acids with lipids. Org. Biomol. Chem. 6, 1324-1333.

(7) Krieg, A. M., Tonkinson, J., Matson, S., Zhao, Q., Saxon, M., Zhang, L. M., Bhanja, U., Yakubov, L., and Stein, C. A. (1993) Modification of antisense phosphodiester oligodeoxynucleotides by a $5^{\prime}$ cholesteryl moiety increases cellular association and improves efficacy. Proc. Natl. Acad. Sci. U S A 90, 1048-1052.
(8) Deleavey, G. F., and Damha, M. J. (2012) Designing chemically modified oligonucleotides for targeted gene silencing. Chem. Biol. 19, 937-954.

(9) Shmushkovich, T., Monopoli, K. R., Homsy, D., Leyfer, D., Betancur-Boissel, M., Khvorova, A., and Wolfson, A. D. (2018) Functional features defining the efficacy of cholesterol-conjugated, self-deliverable, chemically modified sirnas. Nucleic Acids Res. 46, 10905-10916.

(10) Nielsen, P. E. (2001) Peptide nucleic acid: A versatile tool in genetic diagnostics and molecular biology. Curr. Opin Biotechnol. 12, 16-20.

(11) Jeong, J. H., Kim, S. W., and Park, T. G. (2003) Novel intracellular delivery system of antisense oligonucleotide by selfassembled hybrid micelles composed of DNA/peg conjugate and cationic fusogenic peptide. Bioconjug. Chem. 14, 473-479.

(12) Chaltin, P., Margineanu, A., Marchand, D., Van Aerschot, A., Rozenski, J., De Schryver, F., Herrmann, A., Mullen, K., Juliano, R., Fisher, M. H., et al. (2005) Delivery of antisense oligonucleotides using cholesterol-modified sense dendrimers and cationic lipids. Bioconjug. Chem. 16, 827-836.

(13) Kundu, A., Nandi, S., and Nandi, A. K. (2017) Nucleic acid based polymer and nanoparticle conjugates: Synthesis, properties and applications. Prog. Mater. Sci. 88, 136-185.

(14) Peng, R., Wang, H., Lyu, Y., Xu, L., Liu, H., Kuai, H., Liu, Q., and Tan, W. (2017) Facile assembly/disassembly of DNA nanostructures anchored on cell-mimicking giant vesicles. J. Am. Chem. Soc. 139, 12410-12413.

(15) Chung, M., and Boxer, S. G. (2011) Stability of DNAtethered lipid membranes with mobile tethers. Langmuir 27, 54925497

(16) Ries, O., Loffler, P. M., and Vogel, S. (2015) Convenient synthesis and application of versatile nucleic acid lipid membrane anchors in the assembly and fusion of liposomes. Org. Biomol. Chem. 13, 9673-9680.

(17) Beales, P. A., and Vanderlick, T. K. (2007) Specific binding of different vesicle populations by the hybridization of membraneanchored DNA. J. Phys. Chem. A 111, 12372-12380.

(18) Stengel, G., Zahn, R., and Hook, F. (2007) DNA-induced programmable fusion of phospholipid vesicles. J. Am. Chem. Soc $129,9584-9585$

(19) Flavier, K. M., and Boxer, S. G. (2017) Vesicle fusion mediated by solanesol-anchored DNA. Biophys. J. 113, 1260-1268. (20) van Lengerich, B., Rawle, R. J., Bendix, P. M., and Boxer, S. G. (2013) Individual vesicle fusion events mediated by lipidanchored DNA. Biophys. J. 105, 409-419.

(21) Beales, P. A., and Vanderlick, T. K. (2014) Application of nucleic acid-lipid conjugates for the programmable organisation of liposomal modules. Adv. Colloid Interfac. 207, 290-305.

(22) Beales, P. A. (2017) Biophysics: A toehold in cell surface dynamics. Nat. Nanotechnol. 12, 404-406.

(23) Loffler, P. M. G., Ries, O., Rabe, A., Okholm, A. H., Thomsen, R. P., Kjems, J., and Vogel, S. (2017) A DNAprogrammed liposome fusion cascade. Angew. Chem. Int. Ed. 56, 13228-13231.

(24) Sellner, S., Kocabey, S., Nekolla, K., Krombach, F., Liedl T., and Rehberg, M. (2015) DNA nanotubes as intracellular delivery vehicles in vivo. Biomaterials 53, 453-463.

(25) Modi, S., Nizak, C., Surana, S., Halder, S., and Krishnan, Y. (2013) Two DNA nanomachines map ph changes along intersecting endocytic pathways inside the same cell. Nat. Nanotechnol. 8, 459467.

(26) Li, J., Fan, C., Pei, H., Shi, J., and Huang, Q. (2013) Smart drug delivery nanocarriers with self-assembled DNA nanostructures. Adv. Mater. 25, 4386-4396

(27) Li, J., Pei, H., Zhu, B., Liang, L., Wei, M., He, Y., Chen, N., Li, D., Huang, Q., and Fan, C. (2011) Self-assembled multivalent DNA nanostructures for noninvasive intracellular delivery of immunostimulatory cpg oligonucleotides. ACS Nano 5, 8783-8789. (28) Angell, C., Xie, S., Zhang, L., and Chen, Y. (2016) DNA nanotechnology for precise control over drug delivery and gene therapy. Small 12, 1117-1132. 
(29) Hu, Q., Li, H., Wang, L., Gu, H., and Fan, C. (2018) DNA nanotechnology-enabled drug delivery systems. Chem. Rev. doi: 10.1021/acs.chemrev.7b00663.

(30) Halley, P. D., Lucas, C. R., McWilliams, E. M., Webber, M. J., Patton, R. A., Kural, C., Lucas, D. M., Byrd, J. C., and Castro, C. E. (2016) Daunorubicin-loaded DNA origami nanostructures circumvent drug-resistance mechanisms in a leukemia model. Small $12,308-320$.

(31) Sellner, S., Kocabey, S., Zhang, T., Nekolla, K., Hutten, S., Krombach, F., Liedl, T., and Rehberg, M. (2017) Dexamethasoneconjugated DNA nanotubes as anti-inflammatory agents in vivo. Biomaterials 134, 78-90.

(32) Surana, S., Shenoy, A. R., and Krishnan, Y. (2015) Designing DNA nanodevices for compatibility with the immune system of higher organisms. Nat. Nanotechnol. 10, 741-747.

(33) Seeman, N. C., and Sleiman, H. F. (2017) DNA nanotechnology. Nat. Rev. Mater. 3, 17068.

(34) Zhang, F., Nangreave, J., Liu, Y., and Yan, H. (2014) Structural DNA nanotechnology: State of the art and future perspective. J. Am. Chem. Soc. 136, 11198-11211.

(35) Seeman, N. C. (2010) Nanomaterials based on DNA. Annu. Rev. Biochem. 79, 65-87.

(36) Rothemund, P. W. (2006) Folding DNA to create nanoscale shapes and patterns. Nature 440, 297-302.

(37) Chen, Y. J., Groves, B., Muscat, R. A., and Seelig, G. (2015) DNA nanotechnology from the test tube to the cell. Nat. Nanotechnol. 10, 748-760.

(38) Pinheiro, A. V., Han, D., Shih, W. M., and Yan, H. (2011) Challenges and opportunities for structural DNA nanotechnology. Nat. Nanotechnol. 6, 763-772.

(39) Jones, M. R., Seeman, N. C., and Mirkin, C. A. (2015) Nanomaterials. Programmable materials and the nature of the DNA bond. Science 347, 1260901.

(40) Torring, T., Voigt, N. V., Nangreave, J., Yan, H., and Gothelf, K. V. (2011) DNA origami: A quantum leap for selfassembly of complex structures. Chem. Soc. Rev. 40, 5636-5646.

(41) Sacca, B., and Niemeyer, C. M. (2012) DNA origami: The art of folding DNA. Angew. Chem. Int. Ed. 51, 58-66.

(42) Pugh, G. C., Burns, J. R., and Howorka, S. (2018) Comparing proteins and nucleic acids for next-generation biomolecular engineering. Nat. Rev. Chem. 2, 113-130.

(43) Sprengel, A., Lill, P., Stegemann, P., Bravo-Rodriguez, K., Schoneweiss, E. C., Merdanovic, M., Gudnason, D., Aznauryan, M., Gamrad, L., Barcikowski, S., et al. (2017) Tailored protein encapsulation into a DNA host using geometrically organized supramolecular interactions. Nat. Commun. 8, 14472.

(44) Keum, J. W., and Bermudez, H. (2009) Enhanced resistance of DNA nanostructures to enzymatic digestion. Chem. Commun. 7036-7038.

(45) Walsh, A. S., Yin, H., Erben, C. M., Wood, M. J., and Turberfield, A. J. (2011) DNA cage delivery to mammalian cells. ACS Nano 5, 5427-5432.

(46) Shen, X., Jiang, Q., Wang, J., Dai, L., Zou, G., Wang, Z. G., Chen, W. Q., Jiang, W., and Ding, B. (2012) Visualization of the intracellular location and stability of DNA origami with a label-free fluorescent probe. Chem. Commun. 48, 11301-11303.

(47) Bastings, M. M. C., Anastassacos, F. M., Ponnuswamy, N., Leifer, F. G., Cuneo, G., Lin, C., Ingber, D. E., Ryu, J. H., and Shih, W. M. (2018) Modulation of the cellular uptake of DNA origami through control over mass and shape. Nano Lett. 18, 3557-3564.

(48) Wang, P., Rahman, M. A., Zhao, Z., Weiss, K., Zhang, C., Chen, Z., Hurwitz, S. J., Chen, Z. G., Shin, D. M., and Ke, Y. (2018) Visualization of the cellular uptake and trafficking of DNA origami nanostructures in cancer cells. J. Am. Chem. Soc. 140, 2478-2484.

(49) Akinc, A., and Battaglia, G. (2013) Exploiting endocytosis for nanomedicines. Cold Spring Harb. Perspect. Biol. 5, a016980.

(50) Franquelim, H. G., Khmelinskaia, A., Sobczak, J. P., Dietz, H., and Schwille, P. (2018) Membrane sculpting by curved DNA origami scaffolds. Nat. Commun. 9, 811 .

(51) Khmelinskaia, A., Mucksch, J., Petrov, E. P., Franquelim, H. G., and Schwille, P. (2018) Control of membrane binding and diffusion of cholesteryl-modified DNA origami nanostructures by DNA spacers. Langmuir 34, 14921-14931.

(52) Khmelinskaia, A., Ibarguren, M., de Almeida, R. F., Lopez, D. J., Paixao, V. A., Ahyayauch, H., Goni, F. M., and Escriba, P. V. (2014) Changes in membrane organization upon spontaneous insertion of 2-hydroxylated unsaturated fatty acids in the lipid bilayer. Langmuir 30, 2117-2128.

(53) Burns, J. R., and Howorka, S. (2018) Defined bilayer interactions of DNA nanopores revealed with a nuclease-based nanoprobe strategy. ACS Nano 12, 3263-3271.

(54) Birkholz, O., Burns, J. R., Richter, C. P., Psathaki, O. E. Howorka, S., and Piehler, J. (2018) Multi-functional DNA nanostructures that puncture and remodel lipid membranes into hybrid materials. Nat. Commun. 9, 1521.

(55) Burns, J. R., Seifert, A., Fertig, N., and Howorka, S. (2016) A biomimetic DNA-based channel for the ligand-controlled transport of charged molecular cargo across a biological membrane. Nat. Nanotechnol. 11, 152-156.

(56) Yang, Y., Wang, J., Shigematsu, H., Xu, W., Shih, W. M., Rothman, J. E., and Lin, C. (2016) Self-assembly of size-controlled liposomes on DNA nanotemplates. Nat. Chem. 8, 476-483.

(57) Zhang, Z., Yang, Y., Pincet, F., M, C. L., and Lin, C. (2017) Placing and shaping liposomes with reconfigurable DNA nanocages Nat. Chem. 9, 653-659.

(58) Czogalla, A., Kauert, D. J., Franquelim, H. G., Uzunova, V., Zhang, Y., Seidel, R., and Schwille, P. (2015) Amphipathic DNA origami nanoparticles to scaffold and deform lipid membrane vesicles. Angew. Chem. Int. Ed. 54, 6501-6505

(59) Kocabey, S., Kempter, S., List, J., Xing, Y., Bae, W., Schiffels, D., Shih, W. M., Simmel, F. C., and Liedl, T. (2015) Membrane-assisted growth of DNA origami nanostructure arrays. ACS Nano 9, 3530-3539.

(60) Gopfrich, K., Zettl, T., Meijering, A. E., Hernandez-Ainsa, S., Kocabey, S., Liedl, T., and Keyser, U. F. (2015) DNA-tile structures induce ionic currents through lipid membranes. Nano Lett. $15,3134-3138$.

(61) Johnson-Buck, A., Jiang, S., Yan, H., and Walter, N. G. (2014) DNA-cholesterol barges as programmable membraneexploring agents. ACS Nano 8, 5641-5649.

(62) Xu, W., Nathwani, B., Lin, C., Wang, J., Karatekin, E., Pincet, F., Shih, W., and Rothman, J. E. (2016) A programmable DNA origami platform to organize snares for membrane fusion. $J$. Am. Chem. Soc. 138, 4439-4447.

(63) Perrault, S. D., and Shih, W. M. (2014) Virus-inspired membrane encapsulation of DNA nanostructures to achieve in vivo stability. ACS Nano 8, 5132-5140.

(64) Langecker, M., Arnaut, V., Martin, T. G., List, J., Renner, S., Mayer, M., Dietz, H., and Simmel, F. C. (2012) Synthetic lipic membrane channels formed by designed DNA nanostructures. Science 338, 932-936.

(65) Seifert, A., Göpfrich, K., Burns, J. R., Fertig, N., Keyser, U. F., and Howorka, S. (2015) Bilayer-spanning DNA nanopores with voltage-switching between open and closed state. ACS Nano 9, 1117-1126.

(66) Wu, N., Chen, F., Zhao, Y., Yu, X., Wei, J., and Zhao, Y. (2018) Functional and biomimetic DNA nanostructures on lipid membranes. Langmuir 34, 14721-14730.

(67) Chidchob, P., Offenbartl-Stiegert, D., McCarthy, D., Luo, X., Li, J. N., Howorka, S., and Sleiman, H. F. (2019) Spatial presentation of cholesterol units on a DNA cube as a determinant of membrane protein-mimicking functions. J. Am. Chem. Soc. 141, 1100-1108.

(68) Hughes, L. D., Rawle, R. J., and Boxer, S. G. (2014) Choose your label wisely: Water-soluble fluorophores often interact with lipid bilayers. PLOS ONE 9, e87649.

(69) Bewersdorff, T., Vonnemann, J., Kanik, A., Haag, R., and Haase, A. (2017) The influence of surface charge on serum protein interaction and cellular uptake: Studies with dendritic polyglycerols and dendritic polyglycerol-coated gold nanoparticles. Int. J. Nanomedicine 12, 2001-2019. 
(70) Lundqvist, M., Stigler, J., Cedervall, T., Berggard, T., Flanagan, M. B., Lynch, I., Elia, G., and Dawson, K. (2011) The evolution of the protein corona around nanoparticles: A test study. ACS Nano 5, 7503-7509.

(71) Monopoli, M. P., Walczyk, D., Campbell, A., Elia, G., Lynch, I., Bombelli, F. B., and Dawson, K. A. (2011) Physicalchemical aspects of protein corona: Relevance to in vitro and in vivo biological impacts of nanoparticles. J. Am. Chem. Soc. 133, 25252534 .

(72) Chen, B., Le, W., Wang, Y., Li, Z., Wang, D., Ren, L., Lin, L., Cui, S., Hu, J. J., Hu, Y., et al. (2016) Targeting negative surface charges of cancer cells by multifunctional nanoprobes. Theranostics 6, 1887-1898.

(73) Pekker, M., and Shneider, M. N. (2016) The surface charge of a cell lipid membrane. J. Phys. Chem. Biophys. 5, 177.

(74) Lee, D. S., Qian, H., Tay, C. Y., and Leong, D. T. (2016) Cellular processing and destinies of artificial DNA nanostructures. Chem. Soc. Rev. 45, 4199-4225.

(75) Kocabey, S., Meinl, H., MacPherson, I. S., Cassinelli, V., Manetto, A., Rothenfusser, S., Liedl, T., and Lichtenegger, F. S. (2014) Cellular uptake of tile-assembled DNA nanotubes. Nanomaterials (Basel) 5, 47-60.

(76) de Smidt, P. C., Le Doan, T., de Falco, S., and van Berkel, T. J. (1991) Association of antisense oligonucleotides with lipoproteins prolongs the plasma half-life and modifies the tissue distribution. Nucleic Acids Res. 19, 4695-4700.

(77) Burns, J. R., Al-Juffali, N., Janes, S. M., and Howorka, S. (2014) Membrane-spanning DNA nanopores with cytotoxic effect. Angew. Chem. Int. Ed. 53, 12466-12470.

(78) Langecker, M., Arnaut, V., List, J., and Simmel, F. C. (2014) DNA nanostructures interacting with lipid bilayer membranes. Acc. Chem. Res. 47, 1807-1815.

(79) Howorka, S. (2016) Nanotechnology. Changing of the guard. Science 352, 890-891.

(80) Burns, J., Stulz, E., and Howorka, S. (2013) Self-assembled DNA nanopores that span lipid bilayers. Nano Lett. 13, 2351-2356.

(81) Maingi, V., Burns, J. R., Uusitalo, J. J., Howorka, S., Marrink, S. J., and Sansom, M. S. (2017) Stability and dynamics of membrane-spanning DNA nanopores. Nat. Commun. 8, 14784.

(82) Howorka, S., and Siwy, Z. (2009) Nanopore analytics: Sensing of single molecules. Chem. Soc. Rev. 38, 2360-2384.
(83) Liu, L., and Wu, H. C. (2016) DNA-based nanopore sensing. Angew. Chem. Int. Ed. 55, 15216-15222.

(84) Stoloff, D. H., and Wanunu, M. (2013) Recent trends in nanopores for biotechnology. Curr. Opin. Biotechnol. 24, 699-704.

(85) Liu, L., Li, T., Zhang, S., Song, P., Guo, B., Zhao, Y., and Wu, H. C. (2018) Simultaneous quantification of multiple cancer biomarkers in blood samples through DNA-assisted nanopore sensing. Angew. Chem. Int. Ed. 57, 11882-11887.

(86) Dutta, P. K., Zhang, Y., Blanchard, A. T., Ge, C., Rushdi, M., Weiss, K., Zhu, C., Ke, Y., and Salaita, K. (2018) Programmable multivalent DNA-origami tension probes for reporting cellular traction forces. Nano Lett. 18, 4803-4811.

(87) Ohmann, A., Li, C. Y., Maffeo, C., Al Nahas, K., Baumann, K. N., Gopfrich, K., Yoo, J., Keyser, U. F., and Aksimentiev, A. (2018) A synthetic enzyme built from DNA flips 10(7) lipids per second in biological membranes. Nat. Commun. 9, 2426.

(88) Erazo-Oliveras, A., Muthukrishnan, N., Baker, R., Wang, T. Y., and Pellois, J. P. (2012) Improving the endosomal escape of cellpenetrating peptides and their cargos: Strategies and challenges. Pharmaceuticals (Basel) 5, 1177-1209.

(89) Burns, J. R., Lamarre, B., Pyne, A. L. B., Noble, J. E., and Ryadnov, M. G. (2018) DNA origami inside-out viruses. ACS Synth. Biol. 7, 767-773.

(90) Varkouhi, A. K., Scholte, M., Storm, G., and Haisma, H. J. (2011) Endosomal escape pathways for delivery of biologicals. $J$ Control. Release 151, 220-228.

(91) De Santis, E., Alkassem, H., Lamarre, B., Faruqui, N., Bella, A., Noble, J. E., Micale, N., Ray, S., Burns, J. R., Yon, A. R., et al. (2017) Antimicrobial peptide capsids of de novo design. Nat. Commun. 8, 2263

(92) Guyader, C. P., Lamarre, B., De Santis, E., Noble, J. E., Slater, N. K., and Ryadnov, M. G. (2016) Autonomously folded alpha-helical lockers promote rnai. Sci. Rep. 6, 35012.

(93) Messager, L., Kim, J., Burns, J. R., Cecchin, D., Hindley, J., Pyne, A., Gaitzsch, J., Battaglia, G., and Howorka, S. (2016) Biomimetic hybrid nanocontainers of designed permeability. Angew. Chem. Int. Ed. 55, 11106-11109. 
Insert Table of Contents artwork here

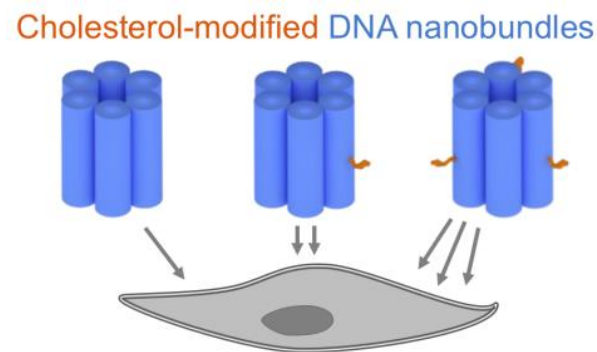

Cell interaction \& uptake 